\title{
Interleukin-12B is upregulated by decoy receptor 3 in rheumatoid synovial fibroblasts
}

\author{
KOJI FUKUDA $^{1}$, YASUSHI MIURA ${ }^{1,2}$, TOSHIHISA MAEDA ${ }^{1}$, SHINYA HAYASHI $^{1}$ and MASAHIRO KUROSAKA ${ }^{1}$ \\ ${ }^{1}$ Department of Orthopaedic Surgery, Kobe University Graduate School of Medicine, Kobe 650-0017; \\ ${ }^{2}$ Division of Orthopedic Science, Department of Rehabilitation Science, \\ Kobe University Graduate School of Health Sciences, Kobe 654-0142, Japan
}

Received March 13, 2015; Accepted January 7, 2016

DOI: $10.3892 / \mathrm{mmr} .2016 .4985$

\begin{abstract}
Decoy receptor 3 (DcR3) competitively binds to three ligands, Fas ligand, lymphotoxin-related inducible ligand that competes for glycoprotein D binding to herpesvirus entry mediator on $\mathrm{T}$ cells and tumor necrosis factor-like ligand 1A (TL1A), to prevent their effects. Recent studies have suggested that DcR3 directly affects cells as a ligand. Using a microarray assay, our group newly identified interleukin (IL)-12B, which encodes the p40 subunit common to IL-12 and IL-23, as one of the genes for which expression in fibroblast-like synoviocytes from patients with rheumatoid arthritis (RA-FLS) is induced by DcR3. The present study demonstrated that IL-12B mRNA expression was upregulated by DcR3-Fc in RA-FLS in a dose-dependent manner, but not in OA-FLS. IL-12B p40 protein in RA-FLS was increased when stimulated with DcR3-Fc. Pre-treatment with anti-TL1A antibody suppressed the upregulation of IL-12B mRNA in RA-FLS stimulated with DcR3-Fc. DcR3 mRNA expression in RA-FLS was induced by IL-23, but not by IL-12. These results indicated that DcR 3 may increase IL-12 or IL-23 by inducing IL-12B p40 expression via membrane-bound TL1A on RA-FLS and that IL-23 reciprocally induces DcR3 expression in RA-FLS. DcR3 and IL-23 may interact in a feedback loop that aggravates local inflammation in patients with RA.
\end{abstract}

\section{Introduction}

Rheumatoid arthritis (RA) is an inflammatory joint disease that features hyperplasia of the synovial tissue and formation of pannus, and their invasive growth into the cartilage,

Correspondence to: Dr Yasushi Miura, Division of Orthopedic Science, Department of Rehabilitation Science, Kobe University Graduate School of Health Sciences, 7-10-2 Tomogaoka, Suma, Kobe 654-0142, Japan

E-mail: miura@kobe-u.ac.jp

Key words: rheumatoid arthritis, fibroblast-like synoviocytes, decoy receptor 3 , interleukin-12B which results in the destruction of cartilage and bone (1). Inflammatory cytokines, including interleukin (IL)-1 $\beta$, IL-6 and tumor necrosis factor (TNF) $\alpha$, are expressed and functionally active in synovial tissues. Within a complex regulatory network, cytokines are implicated in specific immunological processes that promote chronic inflammation, autoimmunity and tissue destruction (2).

Decoy receptor 3 (DcR3)/TR6/M68/TNFRSF6b is a member of the TNF receptor (TNFR) superfamily, but is a secreted protein, as it lacks the transmembrane domain of conventional TNFRs (3). The three ligands of DcR3 are the TNF superfamily members Fas ligand, lymphotoxin-related inducible ligand that competes for glycoprotein D binding to herpesvirus entry mediator on $\mathrm{T}$ cells (LIGHT) and TNF-like ligand 1A (TL1A) (4). Death receptor 3 (DR3) is the receptor for TL1A that induces apoptosis and the activation of nuclear factor $\kappa$-light-chain-enhancer in activated B cells. DcR3 antagonizes TL1A/DR3 signaling event (5). DcR3 is expressed in certain types of normal tissues, including the colon, stomach, spleen, lymph nodes, spinal cord, pancreas and lungs $(3,6)$, but not in NIH3T3 human fibroblast cells (7); furthermore, DcR3 is frequently overexpressed in various tumor cell types $(3,6,8)$. In tumors, overexpression of DcR3 may facilitate the evasion of the cytotoxic and regulatory effects of Fas ligand (3,9), LIGHT (10) and TL1A (5). A previous study by our group reported that DcR3 is expressed in fibroblast-like synoviocytes from patients with rheumatoid arthritis (RA-FLS) and that DcR3 expression induced in RA-FLS by TNF $\alpha$ protected the cells from Fas-induced apoptosis (11). These results led to the hypothesis that DcR3 is a key regulatory molecule for the proliferation of RA-FLS.

Studies have suggested that DcR3 directly induces monocytes to form osteoclasts (12) and that reverse signaling of DcR3 triggers enhanced adhesion of monocytes (13). A previous study by our group also reported that DcR3 induces very late antigen- 4 expression in THP-1 macrophages to inhibit cycloheximide-induced apoptosis (14). Another study by our group found that DcR3 binds to TL1A expressed on RA-FLS, resulting in negative regulation of inflammatory cytokine-induced cell proliferation (15). Furthermore, a comprehensive genetic analysis using microarrays by our group demonstrated that DcR3 regulates gene expression in RA-FLS (16). 
From these gene expression profiles, IL-12B was identified by our group as a gene which is induced by DcR3 in RA-FLS (16). IL-12B encodes the IL-12B p40 subunit, which is common to IL-12 and IL-23 (17). IL-12 consists of IL-12A p35 and IL-12B p40 and induces T-helper cell (Th)1 immune responses, which are linked to autoimmune diseases, including inflammatory bowel disease and psoriasis (18). IL-23 is comprised of IL-23A p19 and IL-12B p40 and is linked to autoimmune diseases, including multiple sclerosis and inflammatory bowel disease, via Th17 immune responses (19). IL-12 (20) and IL-23 $(21,22)$ have also been reported to be associated with the pathogenesis of RA.

The present study demonstrated that DcR3 induces IL-12B p40 expression in RA-FLS by binding to membrane-bound TL1A. In turn, IL-23 upregulates DcR3 expression in RA-FLS. These results suggested that DcR3 and IL-23 may interact in a feedback loop that aggravates local inflammation in patients with RA.

\section{Materials and methods}

Isolation and culture of synovial fibroblasts. Synovial samples were obtained from patients with RA who fulfilled the criteria of the American College of Rheumatology (formerly, the American Rheumatism Association) (23) and who had never been treated with biologics during total hip or knee replacement. Patients included 3 males and 27 females aged 69.0 \pm 10.3 years old. Written informed consent to participate in this study was obtained from all patients in accordance with the World Medical Association Declaration of Helsinki Ethical Principles for Medical Research Involving Human Subjects. The Medicine Ethics Committee of Kobe University Graduate School of Health Sciences (Kobe, Japan) approved the protocol including consent procedures. Synovial samples from patients with osteoarthritis (OA) were obtained during total knee replacement in a similar manner ( 8 females; aged $71.1 \pm 10.6$ years old). To isolate FLS, synovial tissue specimens were minced and digested in Dulbecco's modified Eagle's medium (DMEM; Sigma-Aldrich, St. Louis, MO, USA) containing $0.2 \%$ collagenase (Sigma-Aldrich) for $2 \mathrm{~h}$ at $37^{\circ} \mathrm{C}$. Dissociated cells were cultured in DMEM supplemented with $10 \%$ fetal bovine serum (Sigma-Aldrich) and 100 units/ml penicillin/streptomycin (Meiji Seika Pharma Co., Ltd., Tokyo, Japan). Following incubation overnight and removal of non-adherent cells, adherent cells were further incubated in fresh medium. Cells from passages 3-7 were used in all further experiments (11).

Cell treatments. For quantification of IL-12B mRNA expression in RA-FLS by reverse transcription quantitative polymerase chain reaction (RT-qPCR), cells $\left(1 \times 10^{6} /\right.$ well) were stimulated with 10,100 or $1,000 \mathrm{ng} / \mathrm{ml}$ recombinant human DcR3-Fc chimera protein (DcR3-Fc; R\&D Systems, Minneapolis, MN, USA), $1,000 \mathrm{ng} / \mathrm{ml}$ immunoglobulin (Ig)G1 (R\&D Systems) as a control, or left untreated by incubation in serum-free Opti-MEM medium (Gibco; Thermo Fisher Scientific, Inc., Waltham, MA, USA) for $12 \mathrm{~h}$. Furthermore, RA-FLS ( $1 \times 10^{6}$ cells/well) were stimulated with $1,000 \mathrm{ng} / \mathrm{ml}$ DcR3-Fc for $0,6,12$ and $24 \mathrm{~h}$.

In another experiment, RA-FLS $\left(1 \times 10^{6}\right.$ cells/well) were pre-incubated with $5.0 \mu \mathrm{g} / \mathrm{ml}$ monoclonal mouse anti-human TL1A antibody (clone 6E6; 322204; Biolegend, San Diego,
CA, USA), $5.0 \mu \mathrm{g} / \mathrm{ml}$ mouse IgG1 (BA343; Acris, San Diego, CA, USA) or serum-free Opti-MEM overnight at $37^{\circ} \mathrm{C}$ prior to stimulation with $1,000 \mathrm{ng} / \mathrm{ml} \mathrm{DcR} 3-\mathrm{Fc}$ for $12 \mathrm{~h}$ and analysis of IL-12B mRNA levels by RT-qPCR.

Further batches of RA-FLS $\left(1 \times 10^{6}\right.$ cells/well) were stimulated with 10 or $100 \mathrm{ng} / \mathrm{ml}$ recombinant human IL-12 (R\&D Systems), 10 or $100 \mathrm{ng} / \mathrm{ml}$ recombinant human IL-23 (R\&D Systems) or serum-free Opti-MEM for $12 \mathrm{~h}$ for subsequent assessment of DcR3, TL1A and DR3 mRNA by RT-qPCR.

For quantification of IL-12B mRNA expression in OA-FLS stimulated with DcR3-Fc, cells $\left(1 \times 10^{6} /\right.$ well $)$ were incubated with $1,000 \mathrm{ng} / \mathrm{ml}$ DcR3-Fc or $\mathrm{IgG}_{1}$ in serum-free Opti-MEM for $12 \mathrm{~h}$.

For assessment of the expression of IL-12B p40 protein in RA-FLS by western blot analysis, cells (1x10\%/well) were stimulated with $1,000 \mathrm{ng} / \mathrm{ml} \mathrm{DcR3-Fc,} 1,000 \mathrm{ng} / \mathrm{ml} \mathrm{IgG1}$ or left untreated in serum-free Opti-MEM for $24 \mathrm{~h}$.

RT-qPCR analysis. RA-FLS and OA-FLS were cultured in six-well plates at $1 \times 10^{6}$ cells/well with various stimulants as described above. RNA was extracted using the QIAshredder and RNeasy mini kits (Qiagen, Hilden, Germany) according to the manufacturer's protocols. Oligo (dT)-primed first-strand complementary DNA (cDNA) was synthesized from $2 \mu \mathrm{g}$ total RNA using a High Capacity cDNA Transcription kit (Applied Biosystems; Thermo Fisher Scientific, Inc.). Relative expression levels of mRNA encoding IL-12B p40, DcR3, TL1A and DR3, which also binds to TL1A, were compared using TaqMan ${ }^{\circledR}$ real-time PCR on a StepOne ${ }^{\mathrm{TM}}$ real-time PCR system (Applied Biosystems; Thermo Fisher Scientific, Inc.) as follows: $50^{\circ} \mathrm{C}$ for $2 \mathrm{~min}$ and $95^{\circ} \mathrm{C}$ for $10 \mathrm{~min}$, followed by 45 cycles of $95^{\circ} \mathrm{C}$ for $15 \mathrm{sec}$ and $60^{\circ} \mathrm{C}$ for $1 \mathrm{~min}$. Pre-designed primers and probes for IL-12B (Hs01011518_m1), DcR3 (Hs00187070_m1), TL1A (Hs00270802_s1), DR3 (Hs00600930_g1), and glyceraldehyde-3-phosphate dehydrogenase (GAPDH; Hs99999905_m1) as the control were obtained from Applied Biosystems (Thermo Fisher Scientific, Inc.). Comparative analyses of each of these genes in individual patients were performed using StepOne ${ }^{\mathrm{TM}} 2.1$ software (Applied Biosystems; Thermo Fisher Scientific, Inc.), according to the manufacturer's protocol. All amplifications were conducted in duplicate. mRNA expression levels of each gene were calculated using the comparative threshold cycle ( $\delta \delta \mathrm{Cq})$ method, as previously described (24).

Western blot analysis. Following stimulation, cells were washed on ice and lysed using a solution of protease inhibitor cocktail (Nacalai Tesque Inc., Kyoto, Japan), phosphatase inhibitor cocktail 2/3 (Sigma-Aldrich) and hypotonic lysis buffer, which contained $25 \mathrm{mM}$ Tris (Nacalai Tesque Inc.), $150 \mathrm{mM} \mathrm{NaCl}$ (Sigma-Aldrich), 1\% NP-40 (Wako Pure Chemical Industries, Ltd., Osaka, Japan) and $1.5 \mathrm{mM}$ ethylene glycol tetraacetic acid (Dojindo Molecular Technologies, Inc., Kumamoto, Japan). The lysate was incubated for $40 \mathrm{~min}$ at $4^{\circ} \mathrm{C}$ and was subsequently centrifuged at $20,400 \mathrm{x}$ g for $12 \mathrm{~min}$ at $4^{\circ} \mathrm{C}$ in order to isolate the supernatant containing the cytoplasmic proteins. Cytoplasmic proteins were quantified via the Bradford method using the Bio-Rad Protein Assay Dye Reagent Concentrate (Bio-Rad Laboratories, Inc., Hercules, CA, USA). Following dilution to an equal concentration with hypotonic lysis buffer 
A

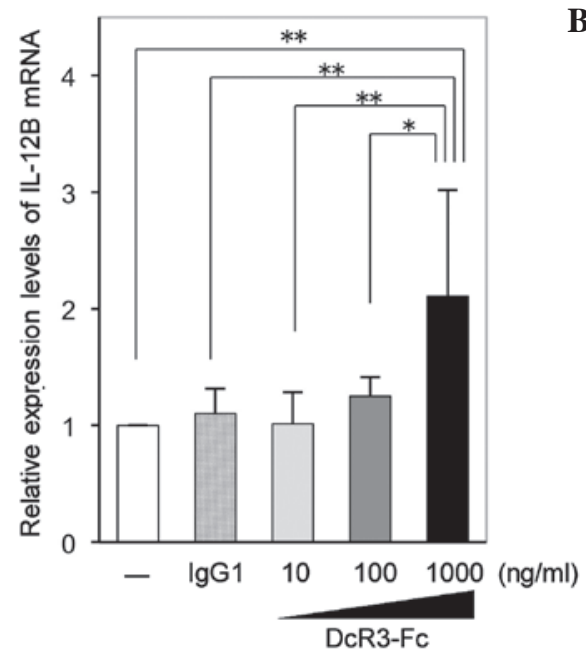

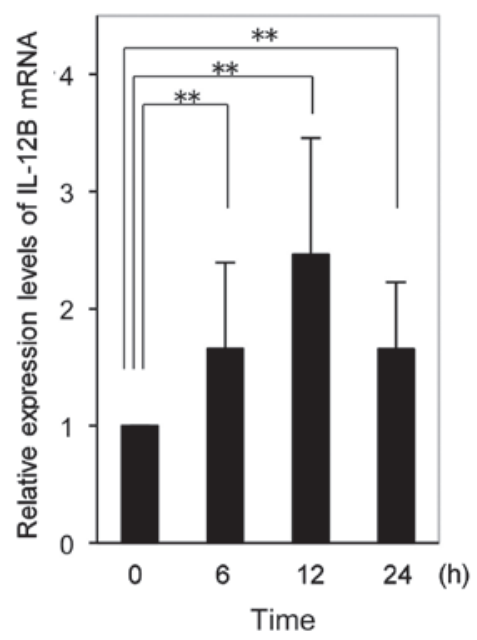

Figure 1. Expression of IL-12B mRNA in RA-FLS. (A) Relative expression levels of IL-12B mRNA in RA-FLS after 12 h of incubation with 10, 100 or $1,000 \mathrm{ng} / \mathrm{ml} \mathrm{DcR3-Fc} \mathrm{or} 1,000 \mathrm{ng} / \mathrm{ml} \mathrm{IgG1}$, or serum-free medium only. Unstimulated cells were assigned a value of 1 . Values are expressed as the mean \pm standard deviation ( $\mathrm{n}=7$ ). (B) Relative expression levels of IL-12B mRNA in RA-FLS after 0, 6, 12 or 24 h of incubation with 1,000 ng/ml DcR3-Fc. Expression at time-point zero was assigned a value of 1 . Values are expressed as the mean \pm standard deviation ( $\mathrm{n}=13$ ). ${ }^{*} \mathrm{P}<0.05 ;{ }^{* *} \mathrm{P}<0.01$. IL, interleukin; IgG, immunoglobulin G; FLS, fibroblast-like synoviocytes; RA, rheumatoid arthritis; DcR3, decoy receptor 3.

(25 mM Tris, $150 \mathrm{mM} \mathrm{NaCl}, 1 \% \mathrm{NP}-40$ and $1.5 \mathrm{mM}$ ethylene glycol tetraacetic acid), each sample was loaded (80 ng/lane) and electrophoresed on a $7.5-15 \%$ polyacrylamide gradient gel (Biocraft, Tokyo, Japan) and electrotransferred onto a blotting membrane (GE Healthcare, Little Chalfont, UK). The membrane was blocked with $0.05 \mathrm{~g} / \mathrm{ml}$ skimmed milk (Megmilk Snow Brand Co., Ltd., Tokyo, Japan) diluted with Tris-buffered saline with Tween ${ }^{\circledR} 20$ [TBST; $20 \mathrm{mM}$ Tris (Nakalai Tesque, Inc.), $150 \mathrm{nM} \mathrm{NaCl}$ (Sigma-Aldrich) and 5\% Tween ${ }^{\circledR} 20$ (Bio-Rad Laboratories, Inc.)] for $1 \mathrm{~h}$ at room temperature. Following washing three times with TBST, the membrane was incubated with primary antibody diluted with Can Get Signal ${ }^{\circledR}$ Immunoreaction Enhancer Solution 1 (Toyobo Co., Ltd., Osaka, Japan) overnight at $4^{\circ} \mathrm{C}$. Following incubation, the membrane was washed three times with TBST and incubated with secondary antibody diluted with Can Get Signal Immunoreaction Enhancer Solution 2 (Toyobo Co., Ltd.) for $1 \mathrm{~h}$ at room temperature.

The expression of IL-12B p40 and $\alpha$-tubulin was detected using mouse anti-human IL-12B p40 antibody (clone 169516; MAB6091; R\&D Systems) and mouse anti-human $\alpha$-tubulin antibody (clone DM1 A; T9026; Sigma-Aldrich) as primary antibodies, respectively. Polyclonal sheep horseradish peroxidase-conjugated anti-mouse IgG antibody (NA931; GE Healthcare) was used as the secondary antibody, and antibodies were visualized using the $\mathrm{ECL}^{\mathrm{TM}}$ plus reagent (GE Healthcare) according to the manufacturer's protocols using the Chemilumino analyzer LAS-3000 mini (FujiFilm, Tokyo, Japan). Protein expression was evaluated by semi-quantification of digitally captured images using the public domain of the US National Institutes of Health Image program (http://rsb.info.nih.gov/nih-image/) with normalization to $\alpha$-tubulin expression.

Statistical analysis. Values are expressed as the mean \pm standard deviation unless otherwise indicated. The Wilcoxon signed-rank test was used to evaluate the differences between
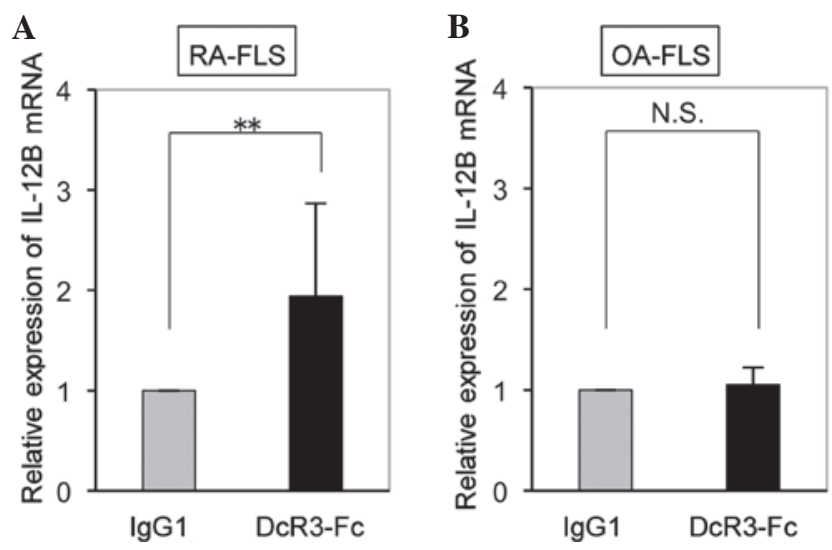

Figure 2. Relative expression of IL-12B mRNA in (A) RA-FLS and (B) OA-FLS after $12 \mathrm{~h}$ of incubation with $1,000 \mathrm{ng} / \mathrm{ml} \mathrm{DcR} 3-\mathrm{Fc}$ or IgG1 in serum-free medium. Expression was normalized against IgG1, which was assigned a value of 1 . Values are expressed as the mean \pm standard deviation ( $\mathrm{n}=7$ for RA-FLS and $\mathrm{n}=8$ for OA-FLS). ${ }^{* *} \mathrm{P}<0.01$. N.S., not significant; IL, interleukin; IgG, immunoglobulin G; RA, rheumatoid arthritis; OA, osteoarthritis; FLS, fibroblast-like synoviocytes; DcR3, decoy receptor 3.

two groups. The Kruskal-Wallis test was used to evaluate the differences among three or more groups. If the Kruskal-Wallis test indicated statistical significance, a post-hoc analysis was performed for these groups. Statistical analyses conducted using Statcel (version 3; OMS Publishing, Inc., Tokyo, Japan). P<0.05 was considered to indicate a statistically significant difference.

\section{Results}

$D c R 3-F c$ increases IL-12B mRNA expression in RA-FLS. RT-qPCR analysis revealed that the expression of IL-12B mRNA in RA-FLS was significantly increased by DcR3-Fc at the highest concentration of $1,000 \mathrm{ng} / \mathrm{ml}$ following incubation for $12 \mathrm{~h}$ (Fig. 1A). Time-course experiments showed that following 6 and $24 \mathrm{~h}$ of stimulation with DcR3-Fc (1,000 $\mathrm{ng} / \mathrm{ml}$ ), the expression of IL-12B mRNA in RA-FLS was 


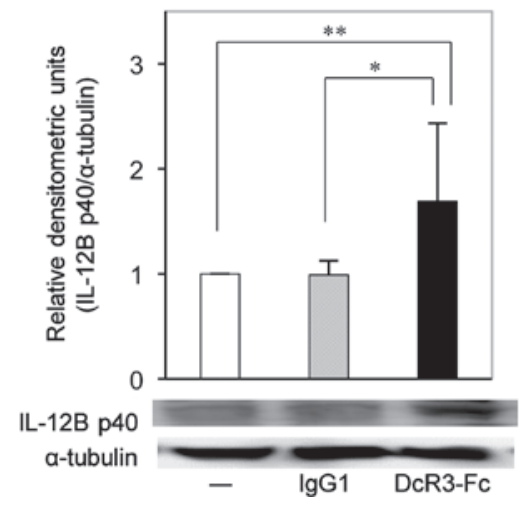

Figure 3. Expression of IL-12B p40 in RA-FLS. Expression levels of IL-12B p40 protein in RA-FLS after $24 \mathrm{~h}$ of incubation with $1,000 \mathrm{ng} / \mathrm{ml}$ DcR3-Fc, $\mathrm{IgG1}$ or medium only. Values are expressed as the mean \pm standard deviation $(\mathrm{n}=7)$. ${ }^{*} \mathrm{P}<0.05 ;{ }^{* *} \mathrm{P}<0.01$. IL, interleukin; IgG, immunoglobulin G; FLS, fibroblast-like synoviocytes; RA, rheumatoid arthritis; DcR3, decoy receptor 3 .

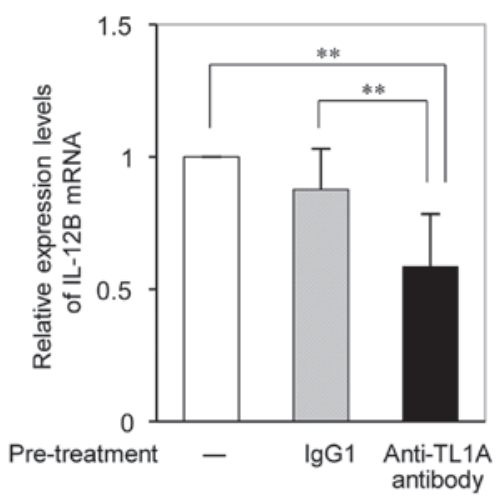

Figure 4. Inhibition of IL-12B mRNA expression in RA-FLS by anti-TL1A antibody. RA-FLS were stimulated with 1,000 ng/ml DcR3-Fc for $12 \mathrm{~h}$ after pre-incubation overnight with $5.0 \mu \mathrm{g} / \mathrm{ml}$ anti-TL1A antibody, IgG1 or medium only. Values are expressed as the mean \pm standard deviation $(n=8)$. ${ }^{* *} \mathrm{P}<0.01$. IL, interleukin; IgG, immunoglobulin G; FLS, fibroblast-like synoviocytes; RA, rheumatoid arthritis; DcR3, decoy receptor 3; TL1A, tumor necrosis factor-like ligand $1 \mathrm{~A}$.

significantly increased to a similar extent and exhibited a peak at $12 \mathrm{~h}$ of stimulation (Fig. 1B).

Upregulation of IL-12B mRNA by DcR3-Fc in FLS is $R A$-specific. While the expression of IL-12B mRNA in RA-FLS was significantly increased by DcR3-Fc (Fig. 2A), it was not affected in OA-FLS (Fig. 2B). This finding suggested that IL-12B mRNA expression was upregulated by DcR3-Fc in FLS an RA-specific manner.

$D c R 3-F c$ increases IL-12B p 40 protein expression in RA-FLS. In accordance with the RT-qPCR results, western blot analysis confirmed that the expression of IL-12B p40 protein in RA-FLS was also significantly increased by DcR3-Fc (Fig. 3).

TL1A antibody suppresses DcR3-induced IL-12B expression in $R A-F L S$. RT-qPCR analysis revealed that the DcR3-Fc-induced increases in IL-12B mRNA expression in RA-FLS were significantly reduced by pre-treatment with anti-TL1A antibody (Fig. 4). While pre-treatment with $\operatorname{IgG}$ as a control slightly but not significantly inhibited DcR3-Fc-induced IL-12B expres-
$\mathbf{A}$

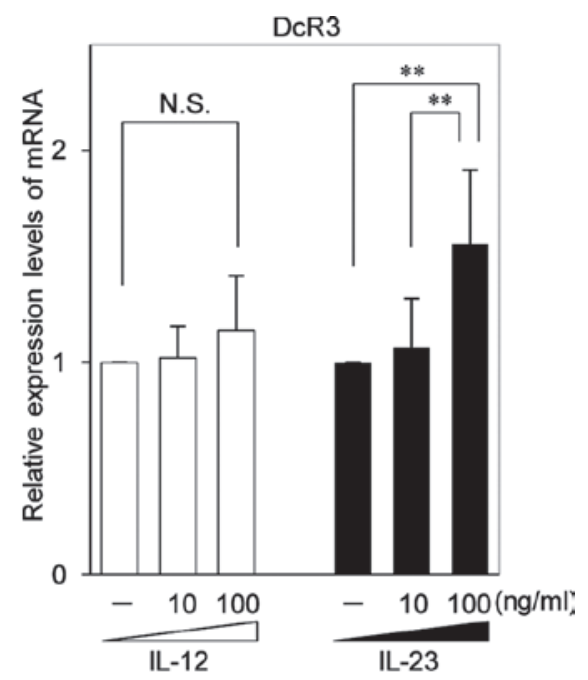

B

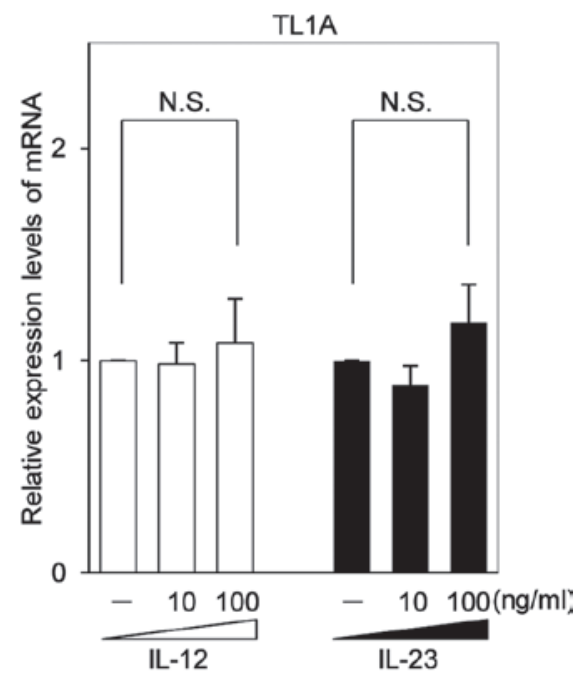

C

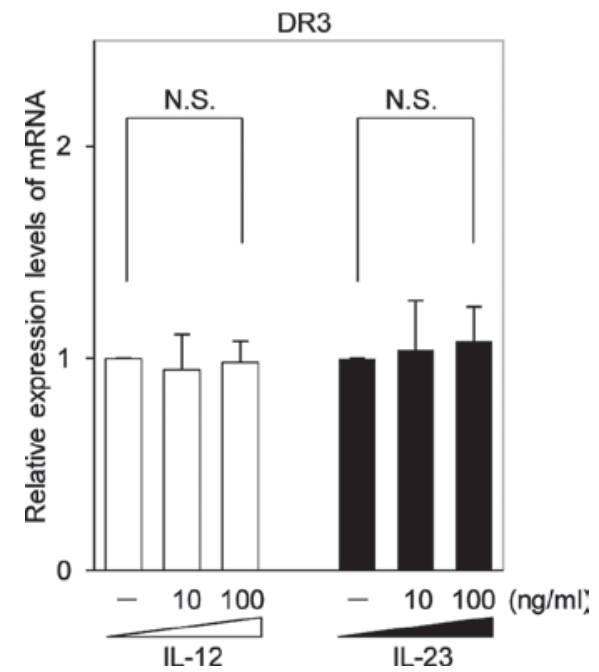

Figure 5. Expression of (A) DcR3, (B) TL1A and (C) DR3 in RA-FLS stimulated with IL-12 or IL-23. Relative mRNA expression levels in RA-FLS were determined after $12 \mathrm{~h}$ of incubation with 0,10 or $100 \mathrm{ng} / \mathrm{ml}$ recombinant human IL-12 or human IL-23. Values are expressed as the mean \pm standard deviation $(\mathrm{n}=8)$. ${ }^{* *} \mathrm{P}<0.01$. N.S., not significant; IL, interleukin; FLS, fibroblast-like synoviocytes; RA, rheumatoid arthritis; DcR3, decoy receptor 3; TL1A, tumor necrosis factor-like ligand 1A; DR3, death receptor 3.

sion, and the effect of anti-TL1A on IL-12B expression was significantly higher. 
IL-23, but not IL-12 induces DcR3 mRNA expression in $R A-F L S$. RT-qPCR revealed that IL-23 induced the expression of DcR3 mRNA, but not that of TL1A or DR3 mRNA, in RA-FLS. However, IL-12 did not induce the expression of DcR3, TL1A or DR3 mRNA (Fig. 5).

\section{Discussion}

Previous studies by our group have demonstrated that DcR3 has a substantial role in local inflammation in RA as a decoy receptor (11) and as a ligand for membrane-bound TL1A $(15,16)$. A recent study by our group used a cDNA microarray assay to reveal the expression profiles of genes regulated by DcR3 in RA-FLS (16). The profile revealed upregulation of IL-12B (fold change, 1.65; $\mathrm{P}=0.008$ ), which was assigned to the major functional clustering categories of cell motility and glycosylation (16). IL-12B mRNA encodes the IL-12B p40 subunit of IL-23 and IL-12. IL-23 regulates Th17 and is involved in the pathogenesis of inflammatory diseases $(19,25,26)$. By contrast, IL-12 shifts the balance of the Th1 vs. the Th2 response towards the Th1 phenotype (18) and induces interferon gamma production via Th1 to be involved in the pathogenesis of inflammatory diseases (27). IL-12 and IL-23 are also key mediators of psoriasis including psoriatic arthritis and are targeted by Ustekinumab, a human anti-p40 monoclonal antibody therapeutic (28). Mannon et al (29) reported that patients with Crohn's disease responded well to treatment with monoclonal antibodies against the p40 subunit of IL-12/IL-23.

The present study confirmed the constitutive expression of IL-12B mRNA and p40 protein in RA-FLS and demonstrated that mRNA and protein expression levels were increased following stimulation with DcR3. Furthermore, while IL-12B mRNA expression was detected in RA-FLS as well as OA-FLS, DcR3 induced overexpression of IL-12B mRNA only in RA-FLS, while not affecting IL-12B expression in OA-FLS. Although the effect of DcR3 on p40 protein expression levels in OA-FLS was not assessed in the present study, it is unlikely to be affected without detectable effects on IL-12B mRNA expression. The results of the present study demonstrated that upregulation of IL-12B mRNA by DcR3-Fc in FLS is disease-specific for $\mathrm{RA}$, as compared with $\mathrm{OA}$ which also causes severe destructive arthritis that may necessitate joint replacement but does not accompany autoimmune abnormality. However, other arthritic conditions are less likely to cause joint destruction, and these should be investigated in future studies.

Sakkas et al (30) showed that the levels of IL-12B mRNA are higher in the synovial membrane of patients with RA than those in patients with OA, although this difference was not statistically significant. Kitagawa et al (31) reported that the level of constitutive IL-12 p40 production by synovial cells (SC) from patients with RA was greater than that by $\mathrm{SC}$ from non-RA patients, including those with $\mathrm{OA}$ and ankylosing spondylitis, and that IL-12 p40 induction by lipopolysaccharide, a potent inducer of IL-12 production in macrophages and dendritic cells, in SC from patients with RA was significantly higher than that in SC from non-RA patients. Combined with the results of the present study, it is therefore suggested that DcR3/IL-12B mediates functions that comprise a disease-specific pathway in RA.
Regarding the mechanisms of the DcR3 - IL-12B interaction, the present study revealed that binding of DcR3 to TL1A, which is expressed on RA-FLS, leads to enhanced expression of IL-12B. In addition, it was demonstrated that IL-23, but not IL-12, induced the expression of DcR3 in RA-FLS. However, the expression of TL1A and DR3 was not affected by either IL-23 or IL-12. These results indicated that DcR3 as a key component of the TL1A/DR3/DcR3 signaling pathway interacts with IL-23 in a feedback loop.

In the present study, the effects of DcR3 on IL-12B mRNA and p40 protein expression levels were investigated. Although the effects of TL1A, Fas ligand and LIGHT on IL-12B and p40 expression levels were were not investigated in the present study, further studies are required in order to assess these effects.

In conclusion, the present study suggested that DcR3 enhances the expression of IL-12B p40 in RA-FLS by binding to membrane-bound TL1A and may increase local IL-23 and IL-12 expression in the rheumatoid synovium. In addition, IL-23, but not IL-12, may induce the expression of DcR3 in RA-FLS. DcR3 and IL-23 may be interact in a feedback loop that aggravates local inflammation in patients with RA. Controlling the expression of local DcR3 or IL-12B may reduce inflammation in the rheumatoid synovium and may represent an approach for developing strategies to treat RA.

\section{Acknowledgements}

The authors would like to thank Mr. Kyoko Tanaka, Ms. Minako Nagata and Ms. Maya Yasuda (Department of Orthopaedic Surgery, Kobe University Graduate School of Medicine) for technical assistance. The present study was supported by a grant-in-aid from the Ministry of Health and Welfare of Japan (grant nos. 24592261 and 15k10473).

\section{References}

1. Goldring SR: Pathogenesis of bone and cartilage destruction in rheumatoid arthritis. Rheumatology (Oxford) 42 (Suppl 2): ii11-ii16, 2003.

2. McInnes IB and Schett G: Cytokines in the pathogenesis of rheumatoid arthritis. Nat Rev Immunol 7: 429-442, 2007.

3. Pitti RM, Marsters SA, Lawrence DA, Roy M, Kischkel FC, Dowd P, Huang A, Donahue CJ, Sherwood SW, Baldwin DT, et al: Genomic amplification of a decoy receptor for Fas ligand in lung and colon cancer. Nature 396: 699-703, 1998.

4. Shi G, Wu Y, Zhang J and Wu J: Death decoy receptor TR6/DcR3 inhibits $\mathrm{T}$ cell chemotaxis in vitro and in vivo. J Immunol 171: 3407-3414, 2003.

5. Migone TS, Zhang J, Luo X, Zhuang L, Chen C, Hu B, Hong JS Perry JW, Chen SF, Zhou JX, et al: TL1A is a TNF-like ligand for DR3 and TR6/DcR3 and functions as a T cell costimulator. Immunity 16: 479-492, 2002.

6. Bai C, Connolly B, Metzker ML, Hilliard CA, Liu X, Sandig V, Soderman A, Galloway SM, Liu Q, Austin CP and Caskey CT: Overexpression of M68/DcR3 in human gastrointestinal tract tumors independent of gene amplification and its location in a four-gene cluster. Proc Natl Acad Sci USA 97: 1230-1235, 2000.

7. Chen J, Zhang L and Kim S: Quantification and detection of DcR3, a decoy receptor in TNFR family. J Immunol Methods 285: 63-70, 2004.

8. Ohshima K, Haraoka S, Sugihara M, Suzumiya J, Kawasaki C, Kanda $\mathrm{M}$ and Kikuchi M: Amplification and expression of a decoy receptor for fas ligand (DcR3) in virus (EBV or HTLV-I) associated lymphomas. Cancer Lett 160: 89-97, 2000.

9. Tsuji S, Hosotani R, Yonehara S, et al: Endogenous decoy receptor 3 blocks the growth inhibition signals mediated by Fas ligand in human pancreatic adenocarcinoma. Int J Cancer 106: $17-25,2003$. 
10. Yu KY, Kwon B, Ni J, Zhai Y, Ebner R and Kwon BS: A newly identified member of tumor necrosis factor receptor superfamily (TR6) suppresses LIGHT-mediated apoptosis. J Biol Chem 274: 13733-13736, 1999

11. Hayashi S, Miura Y, Nishiyama T, Mitani M, Tateishi K, Sakai Y, Hashiramoto A, Kurosaka M, Shiozawa S and Doita M: Decoy receptor 3 expressed in rheumatoid synovial fibroblasts protects the cells against Fas-induced apoptosis. Arthritis Rheum 56: 1067-1075, 2007.

12. Yang CR, Wang JH, Hsieh SL, Wang SM, Hsu TL and Lin WW: Decoy receptor 3 (DcR3) induces osteoclast formation from monocyte/macrophage lineage precursor cells. Cell Death Differ 11 (Suppl 1): S97-S107, 2004

13. Hsu MJ, Lin WW, Tsao WC, Chang YC, Hsu TL, Chiu AW, Chio CC and Hsieh SL: Enhanced adhesion of monocytes via reverse signaling triggered by decoy receptor 3. Exp Cell Res 292: 241-251, 2004.

14. Tateishi K, Miura Y, Hayashi S, Takahashi M and Kurosaka M: DcR3 protects THP-1 macrophages from apoptosis by increasing integrin alpha4. Biochem Biophys Res Commun 389: 593-598, 2009

15. Takahashi M, Miura Y, Hayashi S, Tateishi K, Fukuda K and Kurosaka M: DcR3-TL1A signalling inhibits cytokine-induced proliferation of rheumatoid synovial fibroblasts. Int J Mol Med 28: 423-427, 2011.

16. Fukuda K, Miura Y, Maeda T, Takahashi M, Hayashi S and Kurosaka M: Decoy receptor 3 regulates the expression of various genes in rheumatoid arthritis synovial fibroblasts. Int J Mol Med 32: 910-916, 2013.

17. Lupardus PJ and Garcia KC: The structure of interleukin-23 reveals the molecular basis of p40 subunit sharing with interleukin-12. J Mol Biol 382: 931-941, 2008

18. Haskó G and Szabó C: IL-12 as a therapeutic target for pharmacological modulation in immune-mediated and inflammatory diseases: Regulation of T helper 1/T helper 2 responses. Br J Pharmacol 127: $1295-1304,1999$

19. Paradowska-Gorycka A, Grzybowska-Kowalczyk A, Wojtecka-Lukasik E and Maslinski S: IL-23 in the pathogenesis of rheumatoid arthritis. Scand J Immunol 71: 134-145, 2010.

20. Swaak AJ, van den Brink HG and Aarden LA: Cytokine production in whole blood cell cultures of patients with rheumatoid arthritis Ann Rheum Dis 56: 693-695, 1997.

21. Liu FL, Chen CH, Chu SJ, Chen JH, Lai JH, Sytwu HK and Chang DM: Interleukin (IL)-23 p19 expression induced by IL-1beta in human fibroblast-like synoviocytes with rheumatoid arthritis via active nuclear factor-kappaB and AP-1 dependent pathway. Rheumatology (Oxford) 46: 1266-1273, 2007.
22. Kim HR, Cho ML, Kim KW, Juhn JY, Hwang SY, Yoon CH, Park SH, Lee SH and Kim HY: Up-regulation of IL-23p19 expression in rheumatoid arthritis synovial fibroblasts by IL-17 through PI3-kinase-, NF-kappaB- and p38 MAPK-dependent signalling pathways. Rheumatology (Oxford) 46: 57-64, 2007.

23. Arnett FC, Edworthy SM, Bloch DA, McShane DJ, Fries JF, Cooper NS, Healey LA, Kaplan SR, Liang MH and Luthra HS: The American Rheumatism Association 1987 revised criteria for the classification of rheumatoid arthritis. Arthritis Rheum 31: 315-324, 1988.

24. Thiel CT, Kraus C, Rauch A, Ekici AB, Rautenstrauss B and Reis A: A new quantitative PCR multiplex assay for rapid analysis of chromosome 17p11.2-12 duplications and deletions leading to HMSN/HNPP. Eur J Hum Genet 11: 170-178, 2003.

25. Harrington LE, Hatton RD, Mangan PR, Turner H, Murphy TL, Murphy KM and Weaver CT: Interleukin 17-producing CD4+ effector $\mathrm{T}$ cells develop via a lineage distinct from the T helper type 1 and 2 lineages. Nat Immunol 6: 1123-1132, 2005.

26. Iwakura $\mathrm{Y}$ and Ishigame $\mathrm{H}$ : The IL-23/IL-17 axis in inflammation. J Clin Invest 116: 1218-1222, 2006.

27. Manetti R, Parronchi P, Giudizi MG, Piccinni MP, Maggi E, Trinchieri G and Romagnani S: Natural killer cell stimulatory factor (interleukin 12 [IL-12]) induces T helper type 1 (Th1)-specific immune responses and inhibits the development of IL-4-producing Th cells. J Exp Med 177: 1199-1204, 1993.

28. Gottlieb A and Narang K: Ustekinumab in the treatment of psoriatic arthritis: Latest findings and clinical potential. Ther Adv Musculoskelet Dis 5: 277-285, 2013.

29. Mannon PJ, Fuss IJ, Mayer L, Elson CO, Sandborn WJ, Present D, Dolin B, Goodman N, Groden C, Hornung RL, et al: Anti-interleukin-12 antibody for active Crohn's disease. N Engl J Med 351: 2069-2079, 2004

30. Sakkas LI, Johanson NA, Scanzello CR and Platsoucas CD: Interleukin-12 is expressed by infiltrating macrophages and synovial lining cells in rheumatoid arthritis and osteoarthritis. Cell Immunol 188: 105-110, 1998.

31. Kitagawa M, Mitsui H, Nakamura H, Yoshino S, Miyakawa S, Ochiai N, Onobori M, Suzuki H and Sumida T: Differential regulation of rheumatoid synovial cell interleukin-12 production by tumor necrosis factor alpha and CD40 signals. Arthritis Rheum 42: 1917-1926, 1999. 